\title{
Figure-of-Eight Helicene Carbon Nanohoop with Möbius Topology
}

\author{
Juraj Malinčík, Sudhakar Gaikwad, Marc-Aurèle Boillat, Daniel Häussinger and Tomáš Šolomek* \\ [*] Juraj Malinčík, Dr. Sudhakar Gaikwad, Marc-Aurèle Boillat, Priv.-Doz. Dr. Daniel Häussinger, Dr. Tomáš Šolomek \\ Department of Chemistry, \\ University of Basel, \\ St. Johann's-Ring 19, 4056 Basel (Switzerland) \\ E-mail: tomas.solomek@unibas.ch
}

\begin{abstract}
We present design and synthesis of a new class of chiral figure-of-eight carbon nanohoops by integrating [6]helicene into [7]cycloparaphenylene. The stereogenic [6]helicene unit endows the helicene carbon nanohoop with chiroptical properties and configurational stability typical for higher helicenes, while the presence of radially conjugated oligop-phenylene moiety provides the optoelectronic properties similar to meta[8]cycloparaphenylene, such as emission of visible light with a high quantum yield. We discovered that the synthesized helicene carbon nanohoop possesses a Möbius topology in solution and confirmed this hypothesis by variabletemperature ${ }^{1} \mathrm{H}$ NMR spectroscopy and DFT calculations. Our results suggest that a single helicene stereogenic unit and high molecular strain are sufficient to induce Möbius topology in molecular nanocarbon systems.
\end{abstract}

The synthesis of uniform samples of carbon nanotubes (CNTs), constitutes one of the major challenges in material science. The top-down fabrication methods typically yield ill-defined mixtures of CNTs, in which tubes of different diameter and chirality are present. ${ }^{[1]}$ Therefore, substantial research effort has been invested into the development of a bottom-up synthetic approach from well-defined molecular templates that represent basic fragments of CNTs. ${ }^{[2,3]}$ The seminal synthesis of such templates for armchair CNTs, the hoop-like [n]cycloparaphenylenes ([n]CPPs), has been accomplished for the first time in 2008 by Jasti and Bertozzi ${ }^{[4]}$ and later developed further by groups of Itami, ${ }^{[5,6]}$ Yamago, ${ }^{[7,8]}$ and Osakada. ${ }^{[9]}$

Carbon nanohoops are not only compelling as precursors of CNTs, but they possess unique size-dependent optoelectronic properties as a consequence of their curved nature and radial $\pi$ electron conjugation. ${ }^{[10-12]}$ For example, CPPs display fluorescence, spectrum of which shifts bathochromically with decreasing number of $p$-phenylenes. However, their fluorescence quantum yield decreases with their size, too, and [ $n$ ]CPPs with $n \leq 7$ are non-fluorescent due to the forbidden nature of the $S_{1} \rightarrow S_{0}$ transition. ${ }^{[10,12,13]}$ The fluorescence of the small CPPs can be restored by geometric symmetry breaking. ${ }^{[14-}$ 16] One of the most intuitive ways to decrease the symmetry of a system is to induce chirality. ${ }^{[13]}$ Examples of chiral carbon nanohoops that emerge by replacing a phenylene ring in the structure of CPPs by polycyclic aromatic hydrocarbons such as acenes, ${ }^{[13,17-19]}$ aromatic heterocycles, ${ }^{[20,21]}$ and others ${ }^{[22-24]}$ were investigated both theoretically and experimentally. This allows tuning the emission properties and could, in principle, lead to circularly polarized luminescence (CPL). However, the individual subunits in these segments of chiral CNTs are connected via $\mathrm{C}-\mathrm{C}$ single bonds and, therefore, suffer from low enantiomerization barriers, which hampers the separation and characterization of enantiomers. Strategies to achieve configurationally stable carbon nanohoops have appeared very recently. For instance, Stępieńn ${ }^{[25]}$ and Jasti[i[2] crossed the two half-loops of [n]CPPs $(n \geq 16)$ using 9,9'-bicarbazole and 9,9'-spirobifluorene units, respectively, and thereby locked their structures into a lemniscular shape (Figure 1) with the central subunit as a stereogenic element. The chiroptical properties of the individual enantiomers were studied, however, only in the former case. A similar strategy using a biphenyl as the stereogenic element was developed by Tanaka. ${ }^{[23]}$

Thulin and Wennerström described chiral lemniscular figure-ofeight structures interconnecting two [5]helicenes already in 1976 (Figure 1). ${ }^{[27]}$ Recently, their design has been slightly modified ${ }^{[28-}$ ${ }^{31]}$ and provided compounds with a promising CPL. The planar $\pi-$ electron conjugation of these aromatic systems is topologically equivalent to the radial $\pi$-conjugation in carbon nanohoops, both characterized by even values of the so-called linking number ( $L k$, Figure 1), ${ }^{[20,21,25]}$ which corresponds to the number of half-twists of the $\pi$-surface. As a consequence, all systems discussed above possess two orientable $\pi$-surfaces.

Here, we present and investigate the properties of chiral carbon nanohoop 1 (Figure 1), which emerges by incorporating [6]helicene into the structure of [7]CPP via 2,15-positions in the helicene. Thereby, we created a twisted figure-of-eight molecular structure that possesses a single non-orientable $\pi$-surface with $L k=1$ as a consequence of the unique fusion of the helical stereogenic unit and molecular strain. The [6]helicene endows 1 with chiroptical properties and configurational stability typical for higher helicenes, while the presence of radially-conjugated $p$-phenylene units provides the optoelectronic properties typical for CPPs. 


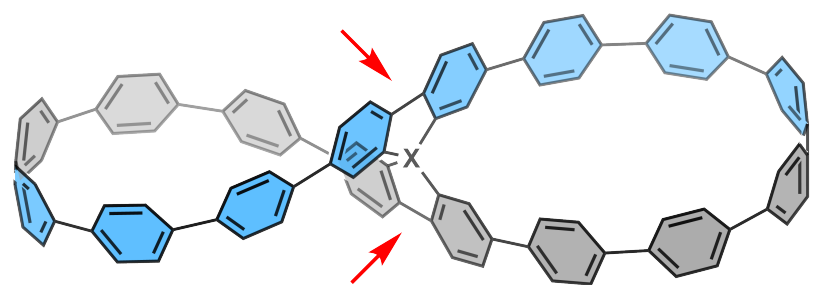

Stępień et al., 2019, $\mathbf{X}=\mathbf{N}-\mathbf{N}$

Jasti et al., 2020, $\mathbf{X}=\mathbf{C}$

$L k=2$

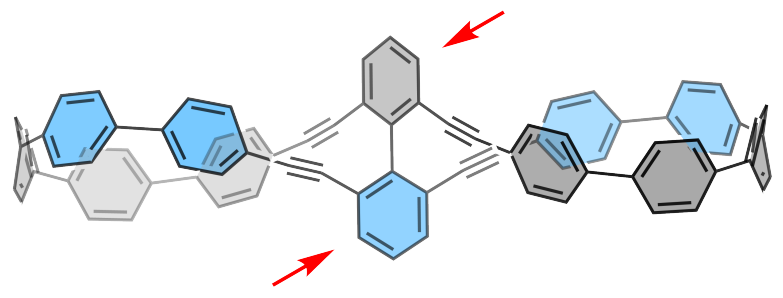

Tanaka et al., 2020

$L k=2$

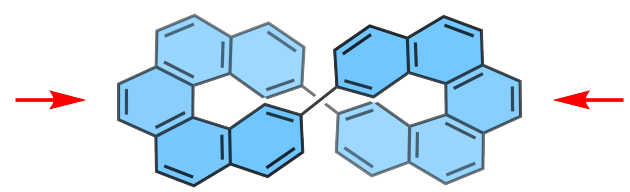

Thulin \& Wennerström, 1976

$L k=2$

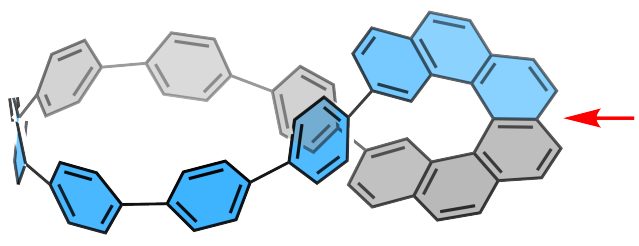

1 , this work

$L k=1$

Figure 1. The structures of figure-of-eight molecular nanocarbons with different stereogenic units. The $L k$ values are the corresponding linking numbers (see text). The light blue and grey colors represent the two different faces of a $p$-phenylene ring and the red arrow denotes a formal half-twist in the aromatic surface.

The synthesis of 1 (Scheme 1) started from commercially available 2,7-dibromonaphthalene, which was transformed to naphthalene-2,7-dicarbaldehyde via Bouveault formylation ${ }^{[32]}$ followed by a double Wittig reaction with (4-bromobenzyl)triphenylphosphonium bromide and subsequent Mallory cyclization. ${ }^{[33]}$ This sequence afforded 2,15-dibromo[6] helicene 2 in $44 \%$ overall yield over the three steps. The synthesis of oligop-phenylene building block commenced from the previously reported compound $3^{\left[{ }^{[16]}\right.}$ which was transformed to diboronate 4 via a double lithium-bromine exchange followed by quenching with $i$-PrOBpin in excellent $99 \%$ yield. The double SuzukiMiyaura cross-coupling of $\mathbf{2}$ and $\mathbf{4}$ followed by deprotection of the silyl protecting groups and subsequent reductive aromatization ${ }^{[8]}$ afforded the target compound $\mathbf{1}$ in $11 \%$ isolated yield over the three steps. So far, our attempts to isolate the intermediate macrocycle (Scheme S3) before the aromatization step have not been successful and we observed a decomposition of the material during column and gel permeation chromatographies. In order to understand the chiroptical properties of 1 , we synthesized the model [6]helicene 5 by Suzuki-Miyaura crosscoupling of $p$-tolueneboronic acid with 2 in $67 \%$ yield.

Compound 1 was fully characterized by high-resolution mass spectrometry and ${ }^{1} \mathrm{H},{ }^{13} \mathrm{C}$, and $2 \mathrm{D}$ NMR spectroscopy (see the $\mathrm{SI})$. The [6]helicene unit acts as a stereogenic element in the structure of 1 . Because our synthesis provided 1 as a racemate, we separated the enantiomers using HPLC equipped with a chiral stationary phase (Figure S1). The measured ECD spectra of the isolated enantiomers appear as mirror images (Figure 2) and we assigned the $M$ - and $P$-configurations to the respective enantiomers by TD-DFT calculations (Figures S21-S24).

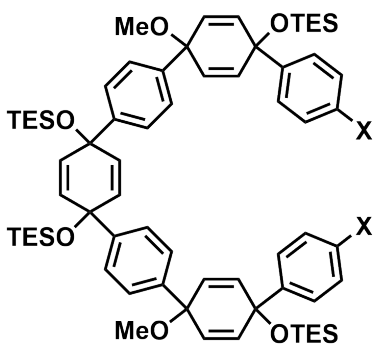<smiles>Brc1ccc2ccc(Br)cc2c1</smiles>

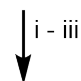

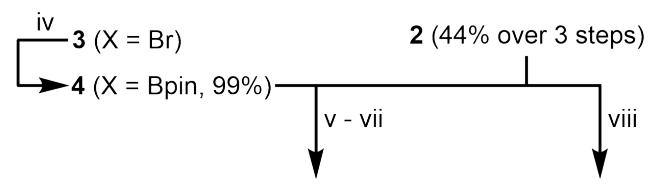

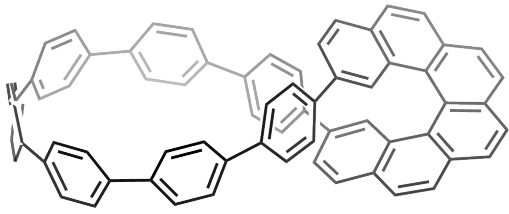

$1(11 \%$ over 3 steps $)$

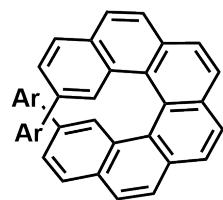

$\mathrm{Ar}=p$-tolyl $5(67 \%)$
Scheme 1. Synthesis of compounds 1 and 5 : i) a) $n$-BuLi, THF, $-78^{\circ} \mathrm{C}, 1$ h. b) DMF, $-78^{\circ} \mathrm{C}$ to r.t.; ii) (4-bromobenzyl)triphenylphosphonium bromide, $\mathrm{NaH}$, THF, r.t., $16 \mathrm{~h}$; iii) propylene oxide, $\mathrm{I}_{2}$, toluene, $h v$, r.t., $4.5 \mathrm{~h}$; iv) a) $n$-BuLi, THF, $-78{ }^{\circ} \mathrm{C}, 1$ h. b) $i$-PrOBpin, $-78{ }^{\circ} \mathrm{C}$ to r.t.; v) $\mathrm{Pd}$ SPhos $\mathrm{G} 3, \mathrm{~K}_{3} \mathrm{PO}_{4}$, dioxane/ $\mathrm{H}_{2} \mathrm{O}$ (10:1), $80^{\circ} \mathrm{C}, 16 \mathrm{~h}$; vi) TBAF, THF, r.t., $1 \mathrm{~h}$; vii) $\mathrm{H}_{2} \mathrm{SnCl}_{4}$, THF, r.t., 1 h; viii) $p$ tolueneboronic acid, $\mathrm{Pd}$ SPhos $\mathrm{G} 3, \mathrm{~K}_{3} \mathrm{PO}_{4}$, dioxane $/ \mathrm{H}_{2} \mathrm{O}(10: 1), 80^{\circ} \mathrm{C}, 24 \mathrm{~h}$. 

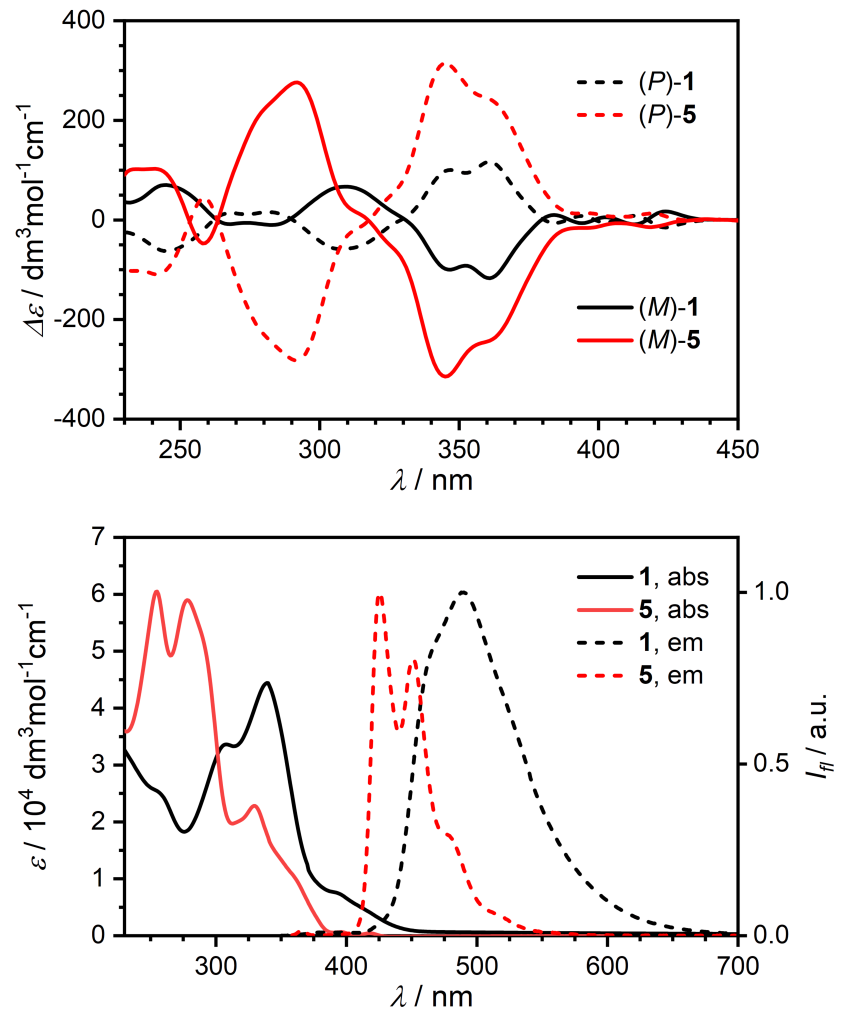

Figure 2. Electronic circular dichroism (top) and absorption and emission (bottom) spectra of samples of $\mathbf{1}$ (black) and $\mathbf{5}$ (red) in $\mathrm{CH}_{2} \mathrm{Cl}_{2}$.

The ECD spectra of the individual enantiomers of $\mathbf{1}$ and $\mathbf{5}$ show that the Cotton bands display the same signs at comparable wavelengths. [6] Helicene is also known to possess a high configurational stability ${ }^{[34,35]}$ with enantiomerization barrier of 35 kcal mol-1 (DFT: 35-38 kcal mol-1, Table S2) that our calculations predict to increase further in 1 due to the presence of the oligo$p$-phenylene half-loop to $\sim 38-44 \mathrm{kcal}^{\mathrm{mol}}{ }^{-1}$, rendering 1 persistent to racemization. Although the chiroptical response of $1(\Delta \varepsilon$, Figure 2$)$ is approximately half of that of $\mathbf{5}$, our results confirm that 1 is endowed with the chiroptical properties and stability that are typical for [6]helicene.

On the other hand, the absorption and emission spectroscopies (Figure 2) show that the electronic structure of 1 and 5 , in fact, differ. For example, the weak $S_{0} \rightarrow S_{1}$ absorption in 1 at $\sim 400 \mathrm{~nm}$ resembles the partially allowed transition of $m[n]$ CPPs with a lower molecular symmetry and the absorption maximum at 339 $\mathrm{nm}$ matches well the most intense transition found in CPPs. ${ }^{[10,16]}$ Unlike the vibronically-resolved fluorescence spectrum of $\mathbf{5}$, the emission of $\mathbf{1}$ is nearly featureless with the emission maximum shifted bathochromically to $\lambda_{\mathrm{em}}=490 \mathrm{~nm}$. The band maximum does not change with the polarity of the solvent. The inspection of the natural transition orbitals (NTOs, Figure 3, Figures S15S18) of the first two electronic transitions shows that the lowest energy transition with a negligible oscillator strength is localized in the [6] helicene unit, while the second, more intense transition, in the oligo-p-phenylene segment. Both transitions are very close in energy. This agrees well with the absorption spectra measured
Transition 1

(3.48 eV, $f=0.098)$
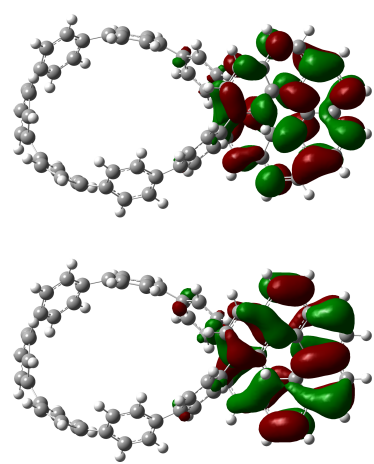

Transition 2

$(3.56 \mathrm{eV}, f=0.152)$
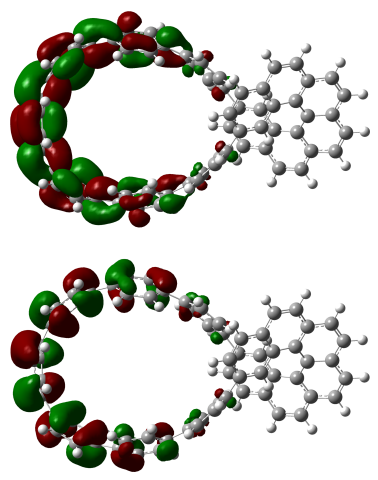

Figure 3. The highest occupied (bottom) and the lowest unoccupied (top) natural transition orbitals of the first (left) and second (right) electronic transitions in 1 calculated at the TD-CAM-B3LYP/6-31G(d) level of theory.

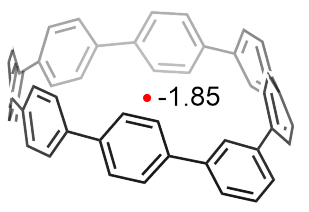

$m[8] \mathrm{CPP}$

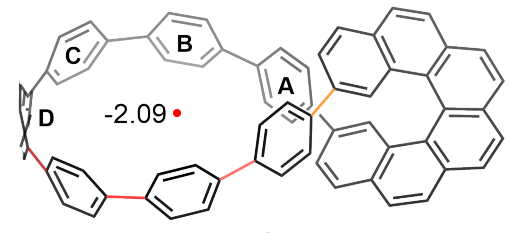

1

$\begin{array}{ccccc}\text { Compound } & \lambda_{\mathrm{em}} / \mathrm{nm} & \Phi_{\mathrm{fl}} & \tau_{\boldsymbol{f l}} / \mathbf{n s} & \text { Strain } / \mathbf{~ k c a l ~ m o l}^{-\mathbf{1}} \\ 1 & 490 & 0.645 & 4.4 & 55.4 \\ \text { [6]Helicene } & 423 & 0.041 & 14.5 & - \\ \text { m[8]CPP } & 484 & 0.60 & 3.4 & 56.7 \\ \text { [10]CPP } & 466 & 0.65 & 6.6 & 57.7\end{array}$

Figure 4. Photophysical properties of 1, [6]helicene,[36] $m[8] \mathrm{CPP},{ }^{[16]}$ and [10]CPP. ${ }^{[12]}$ Strain is the strain energy calculated for individual compounds (see text and the SI). Pairs of $p$-phenylene units in 1 are denoted with capital letters. The strain energy stored in individual $\mathrm{C}-\mathrm{C}$ bonds in 1 increases with the depth of the hue of the red color. The number next to the red dot is the NICS value in the inner void in ppm.

for 1 and 5 ( 400 nm absorption onset, Figure 2). It is expected that the excitation localized in the $p$-phenylene half-loop will possess a larger reorganization energy when compared to the [6]helicene unit due to a larger release of molecular strain (see below) and will become the lowest excited state upon geometry relaxation. As a result, the fluorescence characteristic for the CPPs should be observed. Indeed, the luminescence quantum yield (64.5\%) and the excited state lifetime (4.44 ns) compare well (Figure 4 ) to the photophysical properties of CPPs and differ from the data reported for [6]helicene. ${ }^{[36]}$ The data collected for 1 match those of the symmetry-broken $m[8] \mathrm{CPP}^{[16]}$ (Figure 4), which can be understood by the comparable curvature and radial $\pi$-electron conjugation in these two compounds (see the geometries in Figure S11).

Our DFT calculations revealed a striking structural hallmark in 1, besides the expected figure-of-eight molecular shape. The lowest-energy conformation that we found for 1 suggests that it 
possesses a single non-orientable $\pi$-surface with $L k=1$, i.e., 1 represents a figure-of-eight carbon nanohoop with a Möbius topology. Such systems are predicted to follow the opposite aromaticity rules known to Hückel systems with even $L k^{\prime}$ s. $^{[37]}$ Möbius aromaticity ${ }^{[38]}$ has sparked particular interest after the first successful synthesis of a Möbius-aromatic hydrocarbon by Herges et al. in 2003. ${ }^{[39]}$ However, these systems are rare ${ }^{[30,40,41]}$ because of their complicated synthesis, and their development falters behind that of the Hückel aromatic hydrocarbons. ${ }^{[42]}$

We conducted a conformational search to identify other possible conformations that could be reached by rotation of individual $p$ phenylene units in the structure of 1 . Indeed, we located a conformation with the Hückel topology, which is, however, predicted to be $>5 \mathrm{kcal} \mathrm{mol}^{-1}$ higher in energy than the conformer with the Möbius topology (Figure 5, Table S2). The two structures differ in the orientation of the two $p$-phenylene rings attached directly to the [6] helicene unit. We grew a single-crystal for an Xray diffraction analysis via a vapor-diffusion of $\mathrm{MeOH}$ into a $\mathrm{CHCl}_{3}$ solution of 1 to support our theoretical results. However, the obtained single crystal showed a weak diffraction that only allowed us to determine that 1 crystalized with an orthorhombic unit cell, but the diffraction was insufficient to resolve the crystal structure with an atomic resolution. All other attempts to grow a suitable single crystal from different solvents have been unsuccessful so far. Nevertheless, the energy proximity of the Möbius and the Hückel conformations in 1 suggests that they must interconvert rapidly in a solution on the NMR time scale. Therefore, we performed variable-temperature ${ }^{1} \mathrm{H} \quad$ NMR spectroscopy for a sample of 1 in THF- $d_{8}$ (Figure 5) and TCE- $d_{2}$ (see the $\mathrm{SI}$ ) to support our findings from the DFT calculations. The sharp resonance at $6.34 \mathrm{ppm}$ for ortho-protons in the pair of p-phenylenes (A, Figure 4) adjacent to [6]helicene broadens upon decreasing the temperature and splits into two individual resonances that can be observed at $168 \mathrm{~K}$ at 5.38 and $7.29 \mathrm{ppm}$ (Figure S27). We determined the coalescence temperature $T_{\mathrm{c}}=$ $190 \mathrm{~K}$ and $\Delta G^{\ddagger}=(8.0 \pm 0.12) \mathrm{kcal} \mathrm{mol}^{-1}$ for their chemical exchange. These results are in very good accord with the averaged chemical shifts of 5.22 and 7.15 ppm, respectively, obtained from DFT calculations (Figure 5) for the Möbius conformer of 1 . The NMR rotation barrier also agrees with the computed value of $>7.0 \mathrm{kcal} \mathrm{mol}^{-1}$ (see the SI for further discussion). In addition, the DFT calculations predict that the chemical shifts for the same proton resonances differ markedly in the Hückel conformer of 1 . The results clearly demonstrate that 1 possesses the Möbius topology that arises by integrating a single stereogenic helicene unit and a strained oligo-p-phenylene segment. Compound 1 thus represents one of the conceptually simplest Möbius molecular nanocarbons synthesized to date.

We were able to observe the coalescence also for other proton resonances in 1. We determined the $T_{\mathrm{c}}=248 \mathrm{~K}$ and $\Delta G^{\ddagger}=(11.4$ $\pm 0.12) \mathrm{kcal} \mathrm{mol}^{-1}$ for the protons at 7.36 and $7.69 \mathrm{ppm}(p-$ phenylenes $B$, Figure 4 ), while the rotation of the two remaining $p$-phenylene rings ( $C$ and $D)$ required heating of the NMR sample above room temperature (Figure S26). However, the comparable chemical shifts of the protons in these rings prevented us from determining the exact coalescence temperatures. Nevertheless,
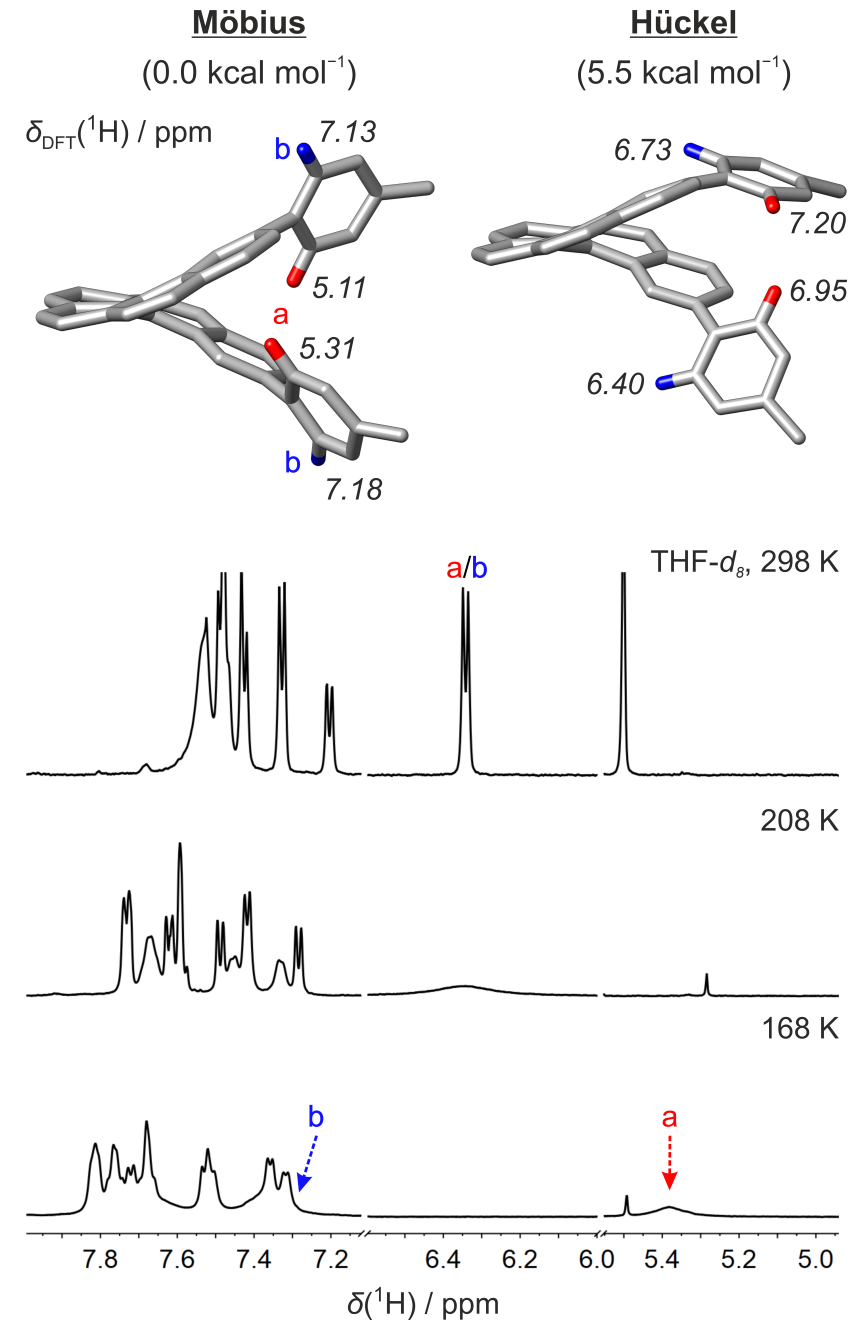

Figure 5. (top) Segment of the structure of the Möbius (left) and Hückel (right) conformation of 1 with the calculated ${ }^{1} \mathrm{H}$ chemical shifts (in ppm, italics) and (bottom) selected spectra from variable-temperature ${ }^{1} \mathrm{H}$ NMR experiments of 1 in THF- $d_{8}$.

we observed that the individual rotational barriers increase with the distance of the $p$-phenylene from the [6]helicene unit $(D>C$ $>\mathrm{B}>\mathrm{A}$ ) and correlate with the distribution of the strain energy within the $p$-phenylene half-loop in 1 (Figures 4 and S10). Thus, a higher strain stored in the $\mathrm{C}-\mathrm{C}$ single bonds connecting the $p$ phenylene rings corresponds to a higher activation free energy of rotation around these bonds. We calculated the strain energy in 1 using StrainViz software, ${ }^{[4]}$ and the homodesmotic reaction depicted in Scheme S5. We obtained the strain energies (Figure 4) of $55.6 \mathrm{kcal} \mathrm{mol}^{-1}$ and $55.4 \mathrm{kcal} \mathrm{mol}^{-1}$, respectively, that compare well to those found for $m[8] \mathrm{CPP}\left(56.7 \mathrm{kcal} \mathrm{mol}^{-1}\right)^{[16]}$ or [10]CPPs $\left(57.7 \mathrm{kcal} \mathrm{mol}^{-1}\right),{ }^{[44]}$ although our values neglect part of the strain in the [6]helicene moiety in $\mathbf{1 .}$

As discussed above, aromatic macrocycles with the odd values of $L k$ may display a global Möbius aromaticity. However, in our case, there is an odd number of $\mathrm{sp}^{2}$-hybridized carbon atoms in the path between the two positions in the [6]helicene unit, via which the $p$-phenylene half-loop is connected. This is in agreement with our calculations of the nucleus-independent 
chemical shifts (NICS, Figure S25) that show only small differences in $\operatorname{NICS}_{z}(1)$ values for individual aromatic rings between the Möbius and Hückel conformations of $\mathbf{1}$ or in $\mathbf{5}$. Similarly, the NICS values calculated in the inner void of 1 are similar to those found in $m[8] \mathrm{CPP}$ (Figure 4) and their values demonstrate the rather global non-aromatic character of these macrocycles. Both the NICS values and the strain energies reinforce our conclusion that compounds similar to 1 preserve the properties of $m[n]$ CPPs due to their structural similarity.

In conclusion, we developed a design strategy that uses a helicene stereogenic unit to induce chirality to a curved $p$ phenylene oligomer providing a concise synthesis of a configurationally stable chiral helicene carbon nanohoop 1 . The enantiomers of the synthesized helicene nanohoop displayed the chiroptical properties and configurational stability typical for [6] helicene, while the presence of curved, radially-conjugated $p$ phenylene segment provided the electronic properties typical for meta[8]cycloparaphenylene, such as emission of blue-green light with a high quantum yield. We then showed, by a combination of variable-temperature NMR experiments and DFT calculations, that the twisted figure-of-eight helicene carbon nanohoop 1 possesses Möbius topology with a single non-orientable $\pi$ surface. Our work thus suggests that integration of a single helicene unit into strained molecular nanocarbons can induce Möbius topology to their structures. The experimental and theoretical investigations of such molecular nanocarbons are ongoing in our laboratory and will be reported in due course.

\section{Acknowledgements}

We thank Prof. Dr. Marcel Mayor for generously hosting our group at the University of Basel and for his invaluable support of our research. We gratefully acknowledge the Department of Chemistry at the University of Basel for the financial support and the computational facilities of the University of Basel (SciCore) for computational resources. We thank Tomáš Pastierik and Prof. Dr. Michal Juriček for their help with the synthesis of [6]helicene and helpful discussions, and Dr. Alessandro Prescimone for the $\mathrm{X}$-ray analysis. The Swiss National Science Foundation (SNSF, PZOOP2_174175, CRSK-2_190341) is gratefully acknowledged for its financial support.

Keywords: molecular nanocarbons • cycloparaphenylenes • helicenes $\cdot$ chirality $\cdot$ Möbius topology

[1] M. C. Hersam, Nat. Nanotechnol. 2008, 3, 387-394.

[2] R. Jasti, C. R. Bertozzi, Chem. Phys. Lett. 2010, 494, 1-7.

[3] H. Omachi, T. Nakayama, E. Takahashi, Y. Segawa, K. Itami, Nat. Chem. 2013, 5, 572-576.

[4] R. Jasti, J. Bhattacharjee, J. B. Neaton, C. R. Bertozzi, J. Am. Chem. Soc. 2008, 130, 17646-17647.

[5] H. Omachi, S. Matsuura, Y. Segawa, K. Itami, Angew. Chem. Int. Ed. 2010, 49, 10202-10205.

[6] Y. Segawa, A. Yagi, K. Matsui, K. Itami, Angew. Chem. Int. Ed. 2016, 55, 5136-5158.

[7] T. Iwamoto, Y. Watanabe, Y. Sakamoto, T. Suzuki, S. Yamago, J. Am. Chem. Soc. 2011, 133, 8354-8361.
[8] V. K. Patel, E. Kayahara, S. Yamago, Chem. Eur. J. 2015, 21, 57425749.

[9] Y. Tsuchido, R. Abe, T. Ide, K. Osakada, Angew. Chem. Int. Ed. 2020, 59, 22928-22932.

[10] Y. Segawa, A. Fukazawa, S. Matsuura, H. Omachi, S. Yamaguchi, S. Irle, K. Itami, Org. Biomol. Chem. 2012, 10, 5979-5984.

[11] M. Fujitsuka, C. Lu, T. Iwamoto, E. Kayahara, S. Yamago, T. Majima, J. Phys. Chem. A 2014, 118, 4527-4532.

[12] E. R. Darzi, R. Jasti, Chem. Soc. Rev. 2015, 44, 6401-6410.

[13] R. Daengngern, C. Camacho, N. Kungwan, S. Irle, J. Phys. Chem. A 2018, 122, 7284-7292.

[14] B. M. Wong, J. W. Lee, J. Phys. Chem. Lett. 2011, 2, 2702-2706.

[15] R. Franklin-Mergarejo, D. O. Alvarez, S. Tretiak, S. Fernandez-Alberti, Sci. Rep. 2016, 6, 31253.

[16] T. C. Lovell, C. E. Colwell, L. N. Zakharov, R. Jasti, Chem Sci 2019, 10, 3786-3790.

[17] H. Omachi, Y. Segawa, K. Itami, Org. Lett. 2011, 13, 2480-2483.

[18] J. Wang, G. Zhuang, Q. Huang, Y. Xiao, Y. Zhou, H. Liu, P. Du, Chem. Commun. 2019, 55, 9456-9459.

[19] P. Della Sala, C. Talotta, M. De Rosa, A. Soriente, S. Geremia, N. Hickey, P. Neri, C. Gaeta, J. Org. Chem. 2019, 84, 9489-9496.

[20] S. M. Bachrach, J. Org. Chem. 2020, 85, 674-681.

[21] S. M. Bachrach, H. S. Rzepa, Chem. Commun. 2020, 56, 1356713570.

[22] E. P. Jackson, T. J. Sisto, E. R. Darzi, R. Jasti, Tetrahedron 2016, 72, 3754-3758.

[23] L.-H. Wang, N. Hayase, H. Sugiyama, J. Nogami, H. Uekusa, K. Tanaka, Angew. Chem. Int. Ed. 2020, 59, 17951-17957.

[24] K. Sato, M. Hasegawa, Y. Nojima, N. Hara, T. Nishiuchi, Y. Imai, Y. Mazaki, Chem. Eur. J. 2021, 27, 1323-1329.

[25] K. Senthilkumar, M. Kondratowicz, T. Lis, P. J. Chmielewski, J. Cybińska, J. L. Zafra, J. Casado, T. Vives, J. Crassous, L. Favereau, M. Stępień, J. Am. Chem. Soc. 2019, 141, 7421-7427.

[26] T. A. Schaub, E. A. Prantl, J. Kohn, M. Bursch, C. R. Marshall, E. J. Leonhardt, T. C. Lovell, L. N. Zakharov, C. K. Brozek, S. R. Waldvogel, S. Grimme, R. Jasti, J. Am. Chem. Soc. 2020, 142, 8763-8775.

[27] B. Thulin, O. Wennerström, B. J. Nielsen, I. Johnson, A. Taticchi, T. Anthonsen, Acta Chem. Scand. 1976, 30b, 688-690.

[28] H. Kubo, D. Shimizu, T. Hirose, K. Matsuda, Org. Lett. 2020, 22, 92769281.

[29] A. Robert, P. Dechambenoit, E. A. Hillard, H. Bock, F. Durola, Chem. Commun. 2017, 53, 11540-11543.

[30] G. Naulet, L. Sturm, A. Robert, P. Dechambenoit, F. Röhricht, R. Herges, H. Bock, F. Durola, Chem. Sci. 2018, 9, 8930-8936.

[31] A. Robert, G. Naulet, H. Bock, N. Vanthuyne, M. Jean, M. Giorgi, Y. Carissan, C. Aroulanda, A. Scalabre, E. Pouget, F. Durola, Y. Coquerel, Chem. Eur. J. 2019, 25, 14364-14369.

[32] V. Církva, P. Jakubík, T. Strašák, J. Hrbáč, J. Sýkora, I. Císařová, J. Vacek, J. Žádný, J. Storch, J. Org. Chem. 2019, 84, 1980-1993.

[33] J. M. Fox, D. Lin, Y. Itagaki, T. Fujita, J. Org. Chem. 1998, 63, 20312038.

[34] R. H. Martin, M.-J. Marchant, Tetrahedron Lett. 1972, 13, 3707-3708.

[35] J. Barroso, J. L. Cabellos, S. Pan, F. Murillo, X. Zarate, M. A. Fernandez-Herrera, G. Merino, Chem. Commun. 2017, 54, 188-191.

[36] J. B. Birks, D. J. S. Birch, E. Cordemans, E. Vander Donckt, Chem. Phys. Lett. 1976, 43, 33-36.

[37] E. Heilbronner, Tetrahedron Lett. 1964, 5, 1923-1928.

[38] H. S. Rzepa, Chem. Rev. 2005, 105, 3697-3715.

[39] D. Ajami, O. Oeckler, A. Simon, R. Herges, Nature 2003, 426, 819821.

[40] R. Herges, Chem. Rev. 2006, 106, 4820-4842.

[41] X. Jiang, J. D. Laffoon, D. Chen, S. Pérez-Estrada, A. S. Danis, J. Rodríguez-López, M. A. Garcia-Garibay, J. Zhu, J. S. Moore, J. Am. Chem. Soc. 2020, 142, 6493-6498.

[42] T. Kawase, M. Oda, Angew. Chem. Int. Ed. 2004, 43, 4396-4398. 
[43] C. E. Colwell, T. W. Price, T. Stauch, R. Jasti, Chem. Sci. 2020, 11, 3923-3930.

[44] Y. Segawa, H. Omachi, K. Itami, Org. Lett. 2010, 12, 2262-2265. 